Nghiên cúu khoa học

\title{
Xây Dựng Hệ Thống Đo Đạc-Báo Cáo-Thẩm Định Cho Các Hoạt Động Giảm Nhẹ Phát Thải Khí Nhà Kính Lĩnh Vực Nông Nghiệp trong NDC của Việt Nam
}

\author{
Phạm Thanh Long ${ }^{1 *}$, Nguyễn Thị Liễu ${ }^{1}$, Đào Minh Trang ${ }^{1}$, Đoàn Quang Trí ${ }^{2}$ \\ ${ }^{1}$ Viện Khoa học Khí tượng Thủy văn và Biến đổi khí hậu; \\ phamthanhlong559@gmail.com; lieuminh2011@gmail.com; daominhtrang@gmail.com \\ 2 Tạp chí Khí tượng Thủy văn, Tổng cục Khí tượng Thủy văn; \\ doanquangtrikttv@gmail.com \\ * Tác giả liên hệ: phamthanhlong559@gmail.com; Tel.: +84-905779777
}

Ban Biên tập nhận bài: 22/8/2020; Ngày phản biện xong: 09/10/2020; Ngày đăng bài: $25 / 11 / 2020$

Tóm tắt: Việt Nam cam kết giảm $9 \%$ lượng phát thải khí nhà kính so với kịch bản phát triển thông thường $(\mathrm{BAU})$ bằng nguồn lực trong nước, có thể giảm tiếp đến $27 \%$ nếu nhận được hỗ trợ quốc tế đến năm 2030 và đã đề xuất nhiều phương án giảm nhẹ phát thải khí nhà kính được đề cập trong Báo cáo đóng góp do quốc gia tự quyết định (NDC). Trong NDC cập nhật, Việt Nam đã phân bổ các mục tiêu giảm thiểu cho 5 lĩnh vực, đặc biệt là năng lượng, nông nghiệp, các quá trình công nghiệp (IP), sử dụng đất, thay đổi sử dụng đất và lâm nghiệp (LULUCF) và chất thải trong giai đoạn 2021-2030. Việc thiết lập hệ thống đo lường, báo cáo và thẩm định (MRV) ở cấp quốc gia và cấp ngành là cần thiết để theo dõi tiến trình hướng tới các mục tiêu giảm nhẹ phát thải KNK. Hiện nay có rất ít nghiên cứu về sắp xếp thể chế và các chỉ số $\mathrm{MRV}$. Nghiên cứu này được thực hiện nhằm phát triển các chỉ số MRV cho các hành động giảm nhẹ KNK trong lĩnh vực nông nghiệp nhằm hỗ trợ các nhà hoạch định chính sách theo dõi việc thực hiện NDC của Việt Nam thông qua các chỉ số: i) Đo lường $\mathrm{KNK}$; (ii) Các chỉ số hành động và tiến độ và (iii) các chỉ số phát triển bền vững dựa trên các nghiên cứu có liên quan và tham vấn chặt chẽ với các chuyên gia trong lĩnh vực nông nghiệp.

Từ khóa: MRV; Sắp xếp thể chế; Chỉ số; Khí nhà kính; Nông nghiệp.

\section{Mở đầu}

Thỏa thuận Paris về biến đổi khí hậu đã được các quốc gia thông qua tại COP 21 như là văn bản pháp lý toàn cầu đầu tiên quy định về ứng phó với biến đổi khí hậu. Trọng tâm của Thỏa thuận Paris là việc đưa ra các quy định liên quan đến trách nhiệm phát triển và thực hiện NDC của mỗi Bên tham gia Công ước khung của Liên hợp quốc về Biến đổi khí hậu (UNFCCC). Cho đến nay, Hiệp định đã được 195 nước ký kết, 179 Bên phê chuẩn và chính thức có hiệu lực từ ngày 4/11/2016.

Mặc dù các quốc gia đã đệ trình NDC vào cuối năm 2015, tuy nhiên, ngay cả khi tất cả $\mathrm{NDC}$ được thực hiện đầy đủ, nhiệt độ trung bình toàn cầu vẫn có thể tăng khoảng $2,9^{\circ} \mathrm{C}$ đến $3,4^{\circ} \mathrm{C}$. Để đạt được mục tiêu $1,5^{\circ} \mathrm{C}$ sẽ yêu cầu không phát thải $\mathrm{KNK}$ toàn cầu trong khoảng thời gian từ 2060-2080 đến khoảng 2080-2090 cho mục tiêu $2^{\circ} \mathrm{C}$. Do đó, Quyết định số 1/CP21 của Thỏa thuận Paris về Biến đổi Khí hậu yêu cầu tất cả các Bên phải rà soát và cập 
nhật NDC của mình ít nhất 5 năm một lần với kỳ vọng tăng tham vọng góp phần giảm nhẹ phát thải KNK. UNFCCC yêu cầu các bên đệ trình NDC sửa đổi lần đầu tiên vào năm 2020 .

Yêu cầu mới nhất là theo Quyết định 18/CMA.1 (2018) là các nước đang phát triển như Việt Nam phải nộp Báo cáo Kiểm kê Quốc gia (NIR) theo Hướng dẫn của IPCC 2006 về Kiểm kê KNK quốc gia (GL 2006) [1] và Tiềm năng nóng lên toàn cầu (GWPs) trong Báo cáo minh bạch hai năm đầu tiên (BTRs) chậm nhất là vào tháng 12 năm 2024. Theo đó, các công việc liên quan đến hệ thống MRV phải đảm bảo sự phù hợp có thể với các yêu cầu báo cáo này và các quy định quốc gia tương ứng, cho đến thời điểm hiện tại, để thực hiện những yêu cầu này. Điều này đặc biệt quan trọng vì bất kỳ cơ chế nào theo Điều 6 của Thỏa thuận Paris $(\mathrm{PA})$ cũng sẽ có tác động đến NDC. Liên quan đến việc báo cáo về giảm phát thải ở cấp quốc gia và cấp ngành, Cuộc họp của các Bên tham gia Hiệp định Paris (CMA) đã không thông qua hướng dẫn chi tiết cho việc thực hiện, báo cáo và kế toán Điều 6 .

Tại COP13, UNFCCC yêu cầu tất cả NAMA (các hành động giảm thiểu phù hợp với quốc gia), dù được hỗ trợ trong nước hay quốc tế, đều phải tuân theo MRV (Lütken và nnk, 2013) [2].

MRV để thực hiện cung cấp thông tin chính để đánh giá mức độ thành công của hoạt động giảm nhẹ, đồng thời, tạo niềm tin cho các bên, đặc biệt là các nhà tài chính để họ tin tưởng rằng các nguồn lực của họ đang được sử dụng hiệu quả để đạt được các mục tiêu đã cam kêt Trong phạm vi rộng hơn, MRV hỗ trợ chương trình phát triển quốc gia và chương trình giảm nhẹ bằng cách cung cấp thông tin liên quan cho các nhà hoạch định chính sách, công chúng và các nguồn tài chính quốc têt [3].

[4] đã đề xuất một cách tiếp cận rộng hơn đối với MRV cho NAMA nhằm giải quyết các nhu cầu về trách nhiệm giải trình và hô̂ trợ đánh giá tác động của NAMA và đóng góp cho phát triển bền vững.

Ngày 24 tháng 7 năm 2020, Thủ tướng Chính phủ đã phê duyệt Cập nhật Đóng góp do quốc gia tự quyết định (NDC) của Việt Nam, trong đó đặt mục tiêu giảm nhẹ phát thải KNK quốc gia $9 \%$ so với kịch bản Kinh doanh như bình thường $(\mathrm{BAU})$ bằng nguồn lực trong nước, và mức đóng góp vô điều kiện có thể tăng lên $27 \%$ nếu Việt Nam nhận được sự hỗ trợ từ quốc tế. Trong NDC cập nhật, Việt Nam đã phân bổ các mục tiêu giảm thiểu cho 5 lĩnh vực, đặc biệt là năng lượng, nông nghiệp, quy trình công nghiệp (IP), sử dụng đất, sử dụng đất và biến đổi lâm nghiệp (LULUCF) và chât thải trong giai đoạn 2021-2030 (Bảng 1). Như vậy, mức đóng góp của lĩnh vực nông nghiệp do quốc gia thực hiện là $0,7 \%$ và lên $2,8 \%$ nếu có sự hỗ trợ từ quốc tế [5].

Bảng 1. Đóng góp về giảm nhẹ phát thải khí nhà kính trong các lĩnh vực.

\begin{tabular}{|c|c|c|c|c|c|c|}
\hline \multirow[b]{2}{*}{ Lĩnh vực } & \multicolumn{2}{|c|}{ Quốc gia tự thực hiện } & \multicolumn{2}{|c|}{$\begin{array}{c}\text { Dự kiến } \\
\text { do quốc tế hỗ trọ̆ }\end{array}$} & \multicolumn{2}{|c|}{$\begin{array}{c}\text { Tổng đóng góp khi có cả hỗ } \\
\text { trọ̣ quốc tế }\end{array}$} \\
\hline & $\begin{array}{c}\text { So với BAU } \\
\text { quốc gia } \\
(\%)\end{array}$ & $\begin{array}{l}\text { Lượng giảm } \\
\text { (Tr. } \mathrm{tCO}_{2} \text { tđ) }\end{array}$ & $\begin{array}{l}\text { So với BAU } \\
\text { quốc gia } \\
(\%)\end{array}$ & $\begin{array}{l}\text { Lượng giảm } \\
\text { (Tr. } \mathrm{tCO}_{2} \text { tđ) }\end{array}$ & $\begin{array}{l}\text { So với BAU } \\
\text { quốc gia } \\
(\%)\end{array}$ & $\begin{array}{l}\text { Lượng giảm } \\
\left(\text { Tr. } \mathrm{tCO}_{2} \text { tđ) }\right.\end{array}$ \\
\hline Năng lượng & 5,5 & 51,5 & 11,2 & 104,3 & 16,7 & 155,8 \\
\hline Nông nghiệp & 0,7 & 6,8 & 2,8 & 25,8 & 3,5 & 32,6 \\
\hline LULUCF* & 1,0 & 9,3 & 1,3 & 11,9 & 2,3 & 21,2 \\
\hline Chất thải & 1,0 & 9,1 & 2,6 & 24,0 & 3,6 & 33,1 \\
\hline $\begin{array}{l}\text { Các quá trình } \\
\text { công nghiệp }\end{array}$ & 0,8 & 7,2 & 0,1 & 0,8 & 0,9 & 8,0 \\
\hline Tổng & 9,0 & 83,9 & 18,0 & 166,8 & 27,0 & 250,8 \\
\hline
\end{tabular}

Ghi chú (*): tăng hấp thụ khí nhà kính 
MRV để thực hiện cung cấp thông tin chính để đánh giá mức độ thành công của hoạt động giảm nhẹ, đồng thời, tạo niềm tin cho các bên, đặc biệt là các nhà tài chính để họ tin tưởng rằng các nguồn lực của họ đang được sử dụng hiệu quả để đạt được các mục tiêu đã cam kết Trong phạm vi rộng hơn, MRV hỗ trợ chương trình phát triển quốc gia và chương trình giảm nhẹ bằng cách cung cấp thông tin liên quan cho các nhà hoạch định chính sách, công chúng và các nguồn tài chính quốc tế. Theo UNEP Risoe (2013), “đo lường” $(\mathrm{M})$ có nghĩa là thu thập thông tin liên quan về tiến độ và tác động giảm thiểu. "Báo cáo" $(\mathrm{R})$ trình bày thông tin đo lường một cách minh bạch và chuẩn hóa. Xác minh $(\mathrm{V})$ ngụ ý đánh giá tính đầy đủ, nhất quán và độ tịn cậy của thông tin được báo cáo thông qua một quá trình độc lập [6] đã đề xuất một cách tiếp cận rộng hơn đối với MRV cho NAMA nhằm giải quyết các nhu cầu về trách nhiệm giải trình và hỗ trợ đánh giá tác động của NAMA và đóng góp cho phát triển bền vững.

Việt Nam đã ban hành Quyết định số 2053/QĐ-TTg của Thủ tướng Chính phủ về việc ban hành Kế hoạch thực hiện Thỏa thuận Paris về biến đổi khí hậu [7]. Một trong những nhiệm vụ chính được đề cập trong Quyết định là thiết lập hệ thống minh bạch cấp quốc gia và cấp ngành về giảm nhẹ phát thải KNK, thích ứng với biến đổi khí hậu và huy động nguồn lực. Ngoài ra, Thông báo Quốc gia lần thứ ba cũng đề xuất một hệ thống MRV cho các hành động giảm nhẹ ở cấp quốc gia [8].

Hiện nay, có một số văn bản pháp luật liên quan có thể là cơ sở tốt cho hệ thống MRV quốc gia ở Việt Nam, bao gồm:

Luật Bảo vệ môi trường sửa đổi được ban hành theo Quyết định số 55/2014/QH13 ngày 23 tháng 6 năm 2014 (thay thế luật cũ năm 2005) với việc bổ sung các điều khoản mới về biến đổi khí hậu. Theo đó, Điều 41, Chương 4 của Luật sửa đổi quy định về quản lý phát thải KNK và xây dựng hệ thống kiểm kê KNK quốc gia [9].

Một trong những nền tảng pháp lý quan trọng cho hệ thống MRV tại Việt Nam là Hệ thống Kiểm kê KNK quốc gia đã được Thủ tướng Chính phủ phê duyệt Quyết định số 2359/ QĐ-TTg năm 2015 [10]. Một trong những mục tiêu cụ thể của Hệ thống Kiểm kê KNK quốc gia là hỗ trợ cho MRV của NAMA và các mục tiêu giảm thiểu do NDC của Việt Nam đặt ra. Hệ thống Kiểm kê KNK quốc gia cũng xây dựng các mẫu báo cáo để các Bộ chủ quản có thể gửi dữ liệu hoạt động của mình trong các lĩnh vực liên quan, đây sẽ là đầu vào cho việc kiểm kê KNK quốc gia. Các mẫu báo cáo này sẽ là cơ sở quan trọng để đo lường và báo cáo các hành động giảm thiểu.

Hệ thống quốc gia kiểm kê khí nhà kính của Việt Nam cũng được xây dựng, trong đó, các số liệu hoạt động trong các lĩnh vực được cung cấp từ các Bộ, ngành liên quan và việc tính toán phát thải/hấp thụ khí nhà kính được thực hiện do các nhóm chuyên gia kỹ thuật do Cục Khí tượng Thủy văn và Biến đổi khí hậu là đơn vị chủ trì.

Tuy nhiên, công tác đảm bảo chất lượng (QA) kiểm kê KNK hiện vẫn còn bỏ ngỏ và là nội dung cần được tiếp tục hoàn thiện trong tương lai, mà phương án thực tế nhất là bổ sung nội dung này vào trong cơ cấu của hệ thống MRV quốc gia (trong đơn vị đầu mối MRV quốc gia-phần trách nhiệm phục vụ xây dựng các báo cáo quốc tế).

Luật Sử dụng năng lượng tiết kiệm và hiệu quả ngày 28/6/2010 quy định về sử dụng năng lượng hiệu quả; các chính sách và giải pháp thúc đẩy sử dụng năng lượng hiệu quả; quyền, nghĩa vụ và trách nhiệm của tổ chức, gia đình, cá nhân trong việc tiết kiệm năng lượng. Bộ Công Thương sẽ có trách nhiệm phối hợp với các cơ quan liên quan về thống kê năng lượng để ban hành chỉ tiêu thống kê năng lượng (Điều 7). MOIT sẽ chịu trách nhiệm thu thập và quản lý dữ liệu năng lượng (Điều 45 ). Ngoài ra, các đơn vị sử dụng năng lượng trọng điểm sẽ phải thực hiện kiểm toán năng lượng ba năm một lần (Điều 33). Có thể nói, Luật Sử dụng năng lượng tiết kiệm và hiệu quả là cơ sở để giám sát các hoạt động sử dụng năng lượng và các giải pháp tiết kiệm năng lượng [10].

Quyết định số 1775/QĐ-TTg ngày 12/11/2012 về Dự án quản lý phát thải KNK và quản lý hoạt động mua bán tín chỉ các-bon ra thị trường thế giới. Dự án cũng đặt ra các mục tiêu 
nâng cao năng lực trong kiểm kê KNK quốc gia và xây dựng các hệ thống MRV quốc gia. Tuy nhiên, hiện tại, các chi tiết cụ thể của các hoạt động liên quan đến MRV vẫn còn hạn chế và chưa đủ để xây dựng và thiết lập hệ thống MRV quốc gia [11].

Quyết định số 3119/QĐ-BNN-KHCN ngày 16 tháng 12 năm 2011 phê duyệt Đề án giảm phát thải khí nhà kính trong nông nghiệp, nông thôn đến năm 2020. Một trong các chương trình, dự án ưu tiên của dự án là "Nghiên cứu và ứng dụng các mô hình tính toán phát thải dựa trên số liệu quan trắc, phương pháp kiểm kê KNK, nhằm hiệu chình đường phát thải cơ sở $\mathrm{KNK}$, giám sát và điều chỉnh mục tiêu và tiềm năng phát thải $\mathrm{KNK}$ (thường xuyên) trong các lĩnh vực nông nghiệp và phát triển nông thôn.

Tại Việt Nam, số lượng các nghiên cứu về MRV vẫn còn hạn chế và thường được thực hiện trong khuôn khổ dự án. Dự án "Hỗ trợ các hành động giảm nhẹ phù hợp với điều kiện quốc gia tại Việt Nam" (Dự án NAMA) đã xác định vai trò, trách nhiệm, nhiệm vụ của các bên liên quan, quy trình chia sẻ thông tin và quy định, bộ thể chế lên hệ thống MRV quốc gia. Nghiên cứu đã trình bày cơ sở lý luận, cách tiếp cận, phương pháp luận và các bước cần thiết để xây dựng hệ thống MRV quốc gia ở Việt Nam, đặc biệt tập trung vào NAMA.

Ngoài ra, trong khuôn khổ dự án NAMA, bộ 149 chỉ số đã được phát triển để theo dõi việc thực hiện 68 nhiệm vụ của Kế hoạch Thực hiện Thỏa thuận Paris (PIPA) được chia thành 5 trụ cột. Có 40 chỉ số để theo dõi các hành động giảm thiểu, 67 chỉ số để theo dõi các hành động thích ứng, 19 chỉ số để theo dõi việc chuẩn bị các nguồn lực, 11 chỉ số về MRV và 12 chỉ số về xây dựng chính sách và thể chế. Trong số 149 chỉ số, chủ yếu có chỉ số tiến độ nhưng cũng có một số chỉ số về kết quả. Năm 2016, nghiên cứu [12] trong khuôn khổ một dự án cấp bộ được thực hiện nhằm phát triển một hệ thống MRV cho các hành động giảm nhẹ ở cấp quốc gia tại Việt Nam. Nghiên cứu đã tổng hợp kinh nghiệm quốc tế về phát triển hệ thống kiểm kê KNK quốc gia và $M R V$ của các hành động giảm thiểu và đề xuất một hệ thống MRV ở cấp quốc gia [12]. Có thể thấy rằng hiện nay rất ít nghiên cứu về $\mathrm{MRV}$ được thực hiện ở Việt Nam và các chỉ số MRV lại càng ít hơn, đặc biệt không có nghiên cứu nào về các chỉ số MRV được phát triển với mục đích cụ thể để theo dõi việc thực hiện các phương án giảm nhẹ trong NDC của Việt Nam nói chung và trong lĩnh vực nông nghiệp nói riêng. Chính vì vậy, nghiên cứu này được thực hiện nhằm xây dựng bộ chỉ số MRV nhằm giám sát tiến độ và kết quả thực hiện của các phương án giảm nhẹ phát thải KNK trong lĩnh vực nông nghiệp đã được đề xuất trong NDC cập nhật của Việt Nam.

\section{Phương pháp nghiên cứu}

\subsection{Cách tiếp cận}

Nghiên cứu này được thực hiện dựa trên việc xem xét và tổng hợp các tài liệu liên quan đến quá trình $M R V$ và các chỉ số để đánh giá hiệu quả của các hành động giảm thiểu. Các chỉ số MRV được xây dựng đặc biệt để theo dõi việc thực hiện các mục tiêu giảm thiểu trong lĩnh vực nông nghiệp của NDC cập nhật, do đó đề xuất các chỉ số MRV được thực hiện dựa trên các mục tiêu và phương án giảm nhẹ trong lĩnh vực nông nghiệp. Cách tiếp cận của nghiên cứu này được minh họa trong Hình 1 . NDC cập nhật của Việt Nam là cơ sở quan trọng để phát triển các chỉ số MRV. Dựa trên các mục tiêu giảm nhẹ trong lĩnh vực nông nghiệp của NDC cập nhật, nghiên cứu đã đề xuất các chỉ số kết quả để theo dõi các mục tiêu giảm nhẹ cho lĩnh vực nông nghiệp. Trong lĩnh vực nông nghiệp, nhóm kỹ thuật NDC đã xác định các phương án giảm thiểu và tiềm năng giảm thiểu của từng phương án. Từ quan điểm đó, các chỉ số kết quả để theo dõi lượng giảm KNK và các chỉ số tiến độ để theo dõi tiến độ của từng phương án giảm nhẹ đã được đề xuất bởi nghiên cứu này.

Thông tin từ việc thu thập và phân tích tài liệu và các nhận xét khác từ tham vấn chuyên gia sẽ là đầu vào quan trọng cho sự phát triển và cải tiến các chỉ số MRV. Cách tiếp cận để thực hiện nghiên cứu này bao gồm 3 bước: 
Bước 1: Xem xét các mục tiêu và các phương án giảm nhẹ KNK trong lĩnh vực nông nghiệp trong báo cáo kỹ thuật cập nhật NDC của Việt Nam. Ngoài ra, nghiên cứu cũng xem xét các nghiên cứu liên quan khác và các văn bản pháp lý hiện hành liên quan đến các hành động giảm nhẹ của lĩnh vực nông nghiệp.

Bước 2: Xây dựng các chỉ số đo KNK dựa trên các mục tiêu và phương án giảm nhẹ trong lĩnh vực nông nghiệp. Trong mỗi phương án, các chỉ số hành động và tiến độ sẽ được xây dựng dựa trên giả định về các phương án giảm nhẹ và yêu cầu báo cáo các chỉ số được đề xuất trong các văn bản pháp luật hiện hành liên quan đến nông nghiệp. Riêng các chỉ tiêu đã có trong các văn bản quy phạm pháp luật hiện hành sẽ được ưu tiên lựa chọn vì sẽ tạo thuận lợi cho quá trình đo lường và báo cáo của các cơ quan trong tương lai. Các chỉ số đo lường phát triển bền vững được phát triển dựa trên nghiên cứu và phân tích mức độ phù hợp của các phương án giảm thiểu đối với phát triển kinh tế, xã hội và môi trường.

Bước 3: Tham khảo ý kiến của các chuyên gia, đặc biệt là các chuyên gia liên quan đến việc xây dựng và cập nhật $\mathrm{BAU}$ và kịch bản giảm thiểu của nông nghiệp trong NDC của Việt Nam.

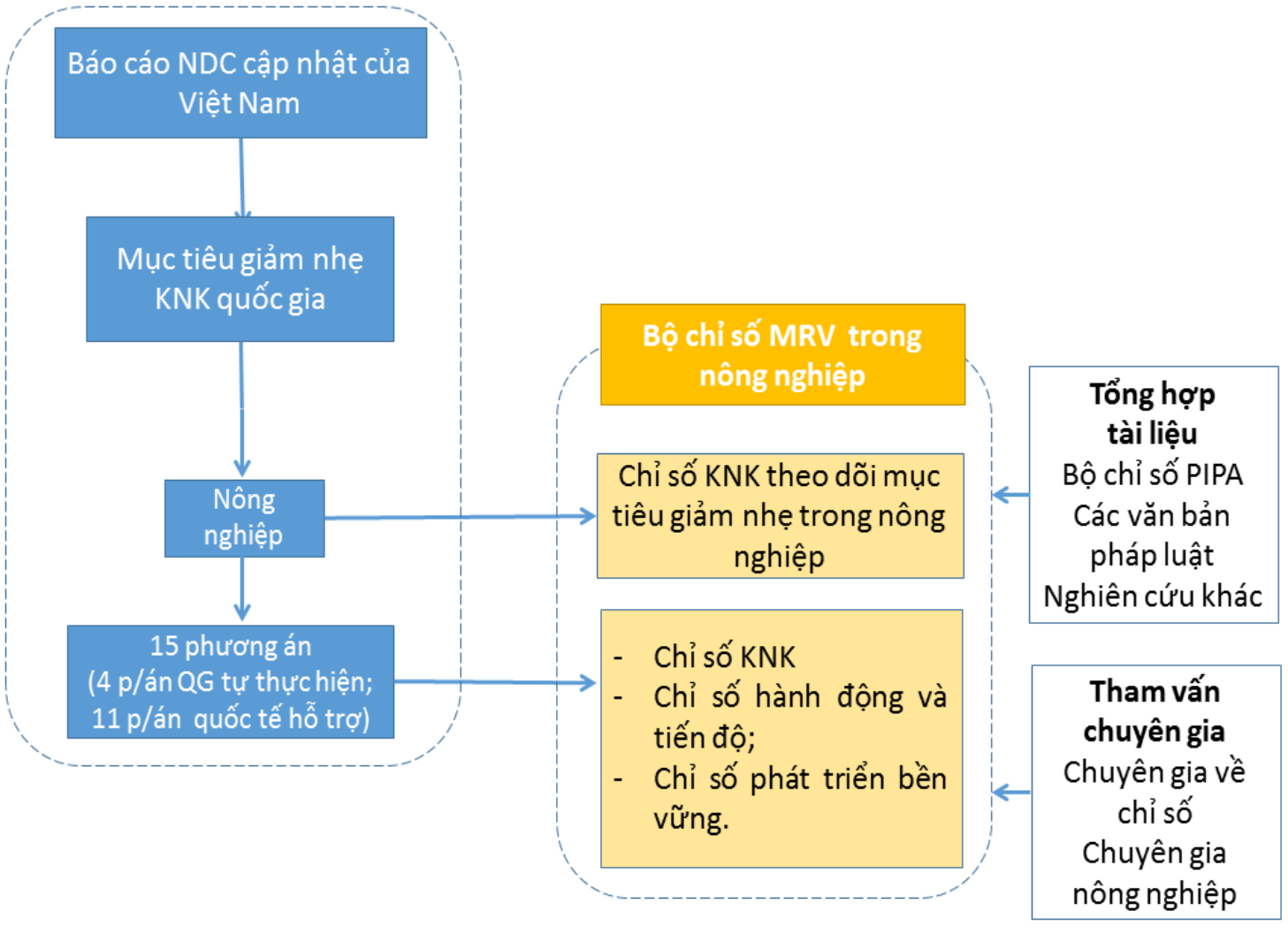

Hình 1. Cách tiếp cận cho việc xây dựng bộ chỉ số MRV cho lĩnh vực nông nghiệp trong NDC của Việt Nam

\subsection{Phuơng pháp và số liệu}

Thông tin về 15 phương án trong lĩnh vực nông nghiệp được thu thập từ báo cáo kỹ thuật cập nhật NDC của Việt Nam và được trình bày cụ thể trong Phụ lục 1 . Trong quá trình xây dựng các chỉ số $M R V$, hai phương pháp nghiên cứu đã được áp dụng, bao gồm nghiên cứu tại bàn và tham khảo ý kiến của các chuyên gia về chỉ số và các chuyên gia liên quan đến việc xây dựng và cập nhật các báo cáo ngành của Việt Nam.

Nghiên cứu tại bàn: Hoạt động này chủ yếu được thực hiện thông qua nghiên cứu bàn về các phương pháp luận/tiêu chuẩn/yêu cầu/thực tiễn tốt nhất được quốc tế công nhận về hệ thống MRV trong các lĩnh vực trong nước và các chỉ số MRV liên quan khác, đặc biệt là 149 
chỉ số để theo dõi việc thực hiện PIPA được phát triển bởi Dự án NAMA) và các nghiên cứu liên quan khác.

Phân tích và đánh giá của chuyên gia: Trên cơ sở nghiên cứu các tiêu chuẩn quốc tế và các thông lệ tốt nhất và thiết kế khuyến nghị của khung tín dụng trong Nhiệm vụ 1 , Tư vấn đã đánh giá các phương án thiết kế MRV khác nhau và đề xuất phương án khả thi nhất. Cân nhắc chính đối với hệ thống $M R V$ là đảm bảo tính nhất quán với hệ thống $M R V$ quốc gia và các quy tắc quốc tế đối với Điều 6 của thỏa thuận Paris cũng như tính khả thi trong bối cảnh của Việt Nam. Hệ thống được phát triển với mục đích sử dụng nó để theo dõi sự đóng góp của lĩnh vực giảm nhẹ trong nước đối với mục tiêu giảm thiểu quốc gia và mức giảm phát thải đạt được. Dựa trên nghiên cứu tại bàn và tham vấn chặt chẽ với các chuyên gia trong ngành nông nghiệp, nghiên cứu này đã đề xuất một quy trình $\mathrm{MRV}$ và các chỉ số để theo dõi tiến độ của các mục tiêu giảm thiểu trong NDC được cập nhật.

\section{Kết quả và thảo luận}

Dựa trên phân loại các chỉ số MRV của CCAP (2012), nghiên cứu này đã xây dựng một bộ chỉ số MRV để theo dõi việc thực hiện các mục tiêu giảm thiểu trong nông nghiệp theo NDC cập nhật của Việt Nam, được chia thành ba loại: (i) Chỉ số KNK (4 chỉ số cho cả lĩnh vực nông nghiệp và 15 chỉ số cho mỗi phương án); (ii) Chỉ số hành động và tiến độ (15 chỉ số) và (iii) chỉ số phát triển bền vững (42 chỉ số).

\subsection{Các chỉ số KNK}

Các chỉ số đo lường KNK bao gồm các chỉ số để theo dõi các mục tiêu giảm nhẹ quốc gia và các chỉ số để theo dõi các mục tiêu giảm nhẹ của ngành trong trường hợp đóng góp vô điều kiện và có điều kiện. Đối với lĩnh vực nông nghiệp, 04 chỉ số đo lường KNK đã được đề xuất, bao gồm:

- Tỷ lệ giảm phát thải KNK trong lĩnh vực nông nghiệp so với BAU nông nghiệp vào năm 2030 trong trường hợp đóng góp vô điều kiện;

- Lượng giảm phát thải KNK trong lĩnh vực nông nghiệp so với BAU nông nghiệp trong trường hợp đóng góp vô điều kiện;

- Tỷ lệ giảm phát thải KNK trong lĩnh vực nông nghiệp so với BAU nông nghiệp vào năm 2030 trong trường hợp đóng góp có điều kiện;

- Lượng giảm phát thải KNK trong lĩnh vực nông nghiệp so với BAU nông nghiệp trong trường hợp đóng góp vô điều kiện.

Ngoài ra, nghiên cứu cũng đề xuất 15 chỉ số đo lường KNK đối với 15 phương án giảm nhẹ KNK.

\subsection{Các chỉ số về hành động và tiến độ}

Ngoài các chỉ số đo lường KNK để theo dõi các mục tiêu giảm thiểu định lượng, nghiên cứu này cũng đề xuất các chỉ số hành động và tiến độ để đánh giá tiến độ đạt được mục tiêu. Các chỉ số hành động và tiến độ này được đề xuất dựa trên mô tả các hành động giảm thiểu trong báo cáo kỹ thuật NDC cập nhật của Việt Nam và các chỉ số hiện có trong các văn bản pháp luật liên quan trong 5 lĩnh vực. Các chỉ số đã có trong các văn bản pháp luật hiện hành sẽ được lựa chọn để tạo điều kiện thuận lợi cho việc đo lường và báo cáo của các bộ trong tương lai. Do đó, việc áp dụng các chỉ số này sẽ khả thi hơn.

Trong lĩnh vực nông nghiệp, 15 chỉ số hành động và tiến độ đã được đề xuất cho 15 phương án dựa trên thông tin về các giả định của mối phương án đến 2030 (Bảng 2). 
Bảng 2. Bộ chỉ số MRV giám sát kết quả và tiến độ thực hiện các hoạt động giảm nhẹ KNK trong lĩnh vực nông nghiệp.

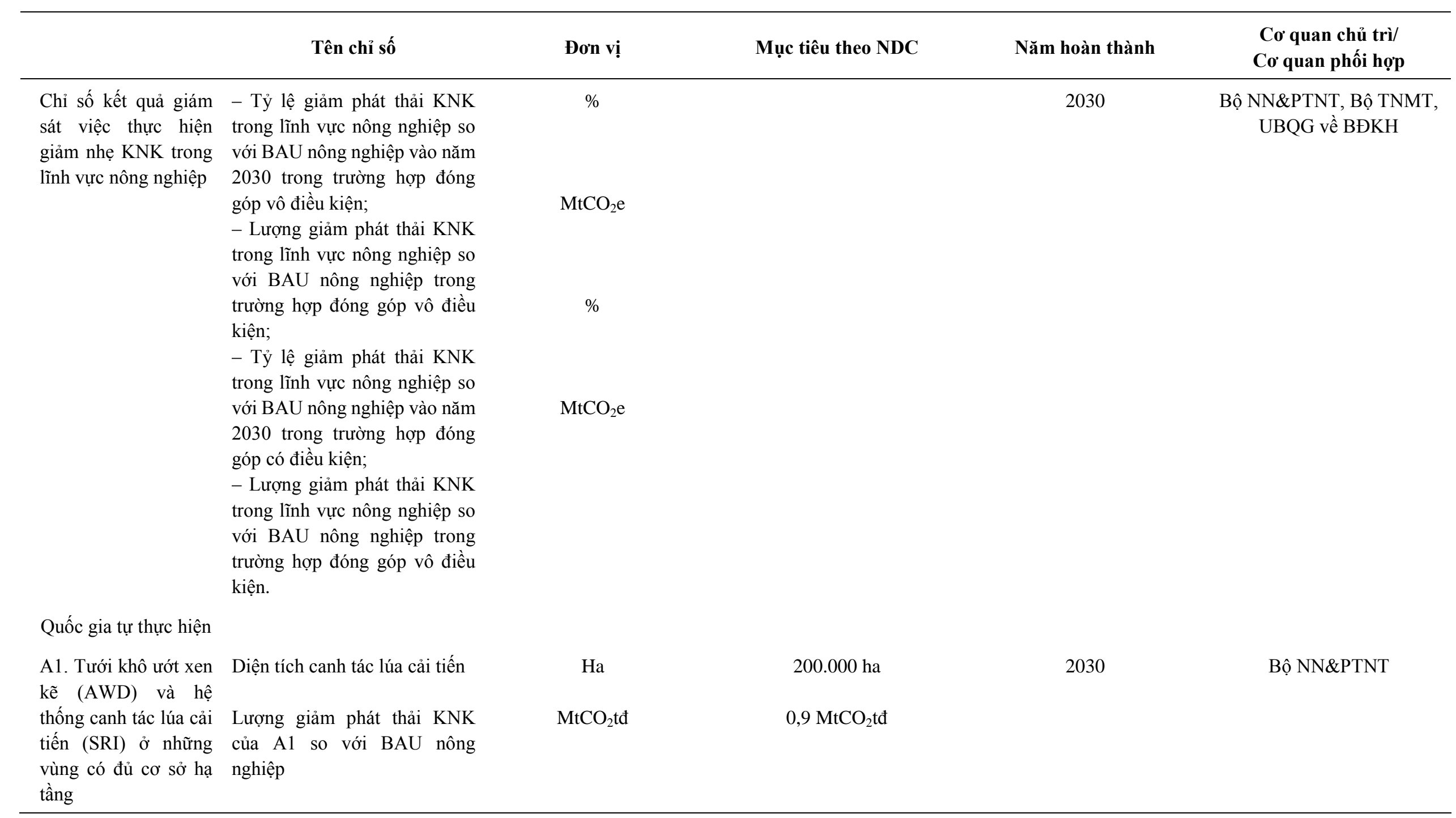




\begin{tabular}{|c|c|c|c|c|c|}
\hline & Tên chỉ số & Đơn vị & Mục tiêu theo NDC & Năm hoàn thành & $\begin{array}{l}\text { Cơ quan chủ trì/ } \\
\text { Cơ quan phối họ̣p }\end{array}$ \\
\hline A2. Rút nước giữa vụ & $\begin{array}{l}\text { Diện tích lúa áp dụng phương } \\
\text { pháp rút nước giữa vụ } \\
\text { Lượng giảm phát thải KNK } \\
\text { của A2 so với BAU nông } \\
\text { nghiệp }\end{array}$ & $\mathrm{MtCO}_{2} \mathrm{td}$ & $3,2 \mathrm{MtCO}_{2} \mathrm{td}$ & 2030 & Bộ NN\&PTNT \\
\hline \multirow[t]{2}{*}{$\begin{array}{l}\text { A3. Chuyển đất } \\
\text { chuyên lúa - lúa } \\
\text { thành lúa - thủy sản }\end{array}$} & $\begin{array}{l}\text { Diện tích chuyên lúa có hiệu } \\
\text { quả thấp và bấp bênh được } \\
\text { chuyển đổi sang hệ thống lúa - } \\
\text { tôm }\end{array}$ & $\mathrm{Ha}$ & 200.000 ha & 2030 & Bộ NN\&PTNT \\
\hline & $\begin{array}{l}\text { Lượng giảm phát thải KNK } \\
\text { của A3 so với BAU nông } \\
\text { nghiệp }\end{array}$ & $\mathrm{MtCO}_{2} \mathrm{tđ}$ & $1,3 \mathrm{MtCO}_{2} \mathrm{tđ}$ & & \\
\hline \multirow[t]{2}{*}{$\begin{array}{l}\text { A4. Chuyển đất } \\
\text { chuyên lúa thành đất } \\
\text { trồng cây trồng cạn }\end{array}$} & $\begin{array}{l}\text { Diện tích đất chuyên lúa có } \\
\text { năng suất bấp bênh và hiệu quả } \\
\text { kém sang trồng cây trồng cạn }\end{array}$ & $\mathrm{Ha}$ & 200.000 ha & 2030 & Bộ NN\&PTNT \\
\hline & $\begin{array}{l}\text { Lượng giảm phát thải KNK } \\
\text { của A4 so với BAU nông } \\
\text { nghiệp }\end{array}$ & $\mathrm{MtCO}_{2} \mathrm{td}$ & $1,4 \mathrm{MtCO}_{2} \mathrm{td}$ & & \\
\hline \multicolumn{6}{|l|}{ Quốc tế hỗ trợ } \\
\hline \multirow{2}{*}{$\begin{array}{l}\text { A5. Cải thiện chất } \\
\text { lượng khẩu phần ăn } \\
\text { cho bò sữa. }\end{array}$} & $\begin{array}{l}\text { Số lượng con bò sữa được cải } \\
\text { thiện khẩu phần ăn }\end{array}$ & Con & 400.000 con & 2030 & Bộ NN\&PTNT \\
\hline & $\begin{array}{l}\text { Lượng giảm phát thải KNK } \\
\text { của A5 so với BAU nông } \\
\text { nghiệp }\end{array}$ & $\mathrm{MtCO}_{2}$ td & $0,1 \mathrm{MtCO}_{2} \mathrm{td}$ & & \\
\hline
\end{tabular}




\begin{tabular}{|c|c|c|c|c|c|}
\hline & Tên chỉ số & Đơn vị & Mục tiêu theo NDC & Năm hoàn thành & $\begin{array}{l}\text { Cơ quan chủ trì/ } \\
\text { Cơ quan phối họpp }\end{array}$ \\
\hline \multirow{3}{*}{$\begin{array}{l}\text { A6. Cải thiện chất } \\
\text { lượng khẩu phần ăn } \\
\text { cho bò thịt. }\end{array}$} & $\begin{array}{l}\text { Số lượng con bò thịt được cải } \\
\text { thiền khẩu phần ăn }\end{array}$ & Con & $2.000 .000 \mathrm{con}$ & 2030 & Bộ NN\&PTNT \\
\hline & $\begin{array}{l}\text { Lượng giảm phát thải KNK } \\
\text { của A6 so với BAU nông } \\
\text { nghiệp }\end{array}$ & $\mathrm{MtCO}_{2} \mathrm{td}$ & $0,3 \mathrm{MtCO}_{2}$ tđ & & \\
\hline & $\begin{array}{l}\text { Số lượng con trâu được cải } \\
\text { thiện khẩu phần ăn }\end{array}$ & Con & 500.000 con & 2030 & Bộ NN\&PTNT \\
\hline $\begin{array}{l}\text { A7. Cải thiện chất } \\
\text { lượng khẩu phần ăn } \\
\text { cho trâu. }\end{array}$ & $\begin{array}{l}\text { Lượng giảm phát thải KNK } \\
\text { của A6 so với BAU nông } \\
\text { nghiệp }\end{array}$ & $\mathrm{MtCO}_{2} \mathrm{td}$ & $0,1 \mathrm{MtCO}_{2}$ tđ & & \\
\hline \multirow{3}{*}{$\begin{array}{l}\text { A8. Tái sử dụng phế } \\
\text { phẩm nông nghiệp. }\end{array}$} & $\begin{array}{l}\text { Diện tích trồng lúa được thu } \\
\text { gom phế phụ phẩm rơm rạ }\end{array}$ & $\mathrm{Ha}$ & 1.200.000 ha & 2030 & Bộ NN\&PTNT \\
\hline & $\begin{array}{l}\text { Lượng giảm phát thải KNK } \\
\text { của A6 so với BAU nông nghiệ }\end{array}$ & $\mathrm{MtCO}_{2} \mathrm{td}$ & $0,1 \mathrm{MtCO}_{2} \mathrm{td}$ & & \\
\hline & $\begin{array}{l}\text { Diện tích quản lý cây trồng } \\
\text { tồng hợp cho lúa }\end{array}$ & $\mathrm{Ha}$ & 1.000 .000 ha & 2030 & Bộ NN\&PTNT \\
\hline $\begin{array}{l}\text { A9. Quản lý cây trồng } \\
\text { tổng hợp (ICM) cho } \\
\text { lúa. }\end{array}$ & $\begin{array}{l}\text { Lượng giảm phát thải KNK } \\
\text { của A6 so với BAU nông } \\
\text { nghiệp }\end{array}$ & $\mathrm{MtCO}_{2}$ td & $0,5 \mathrm{MtCO}_{2} \mathrm{td}$ & & \\
\hline
\end{tabular}




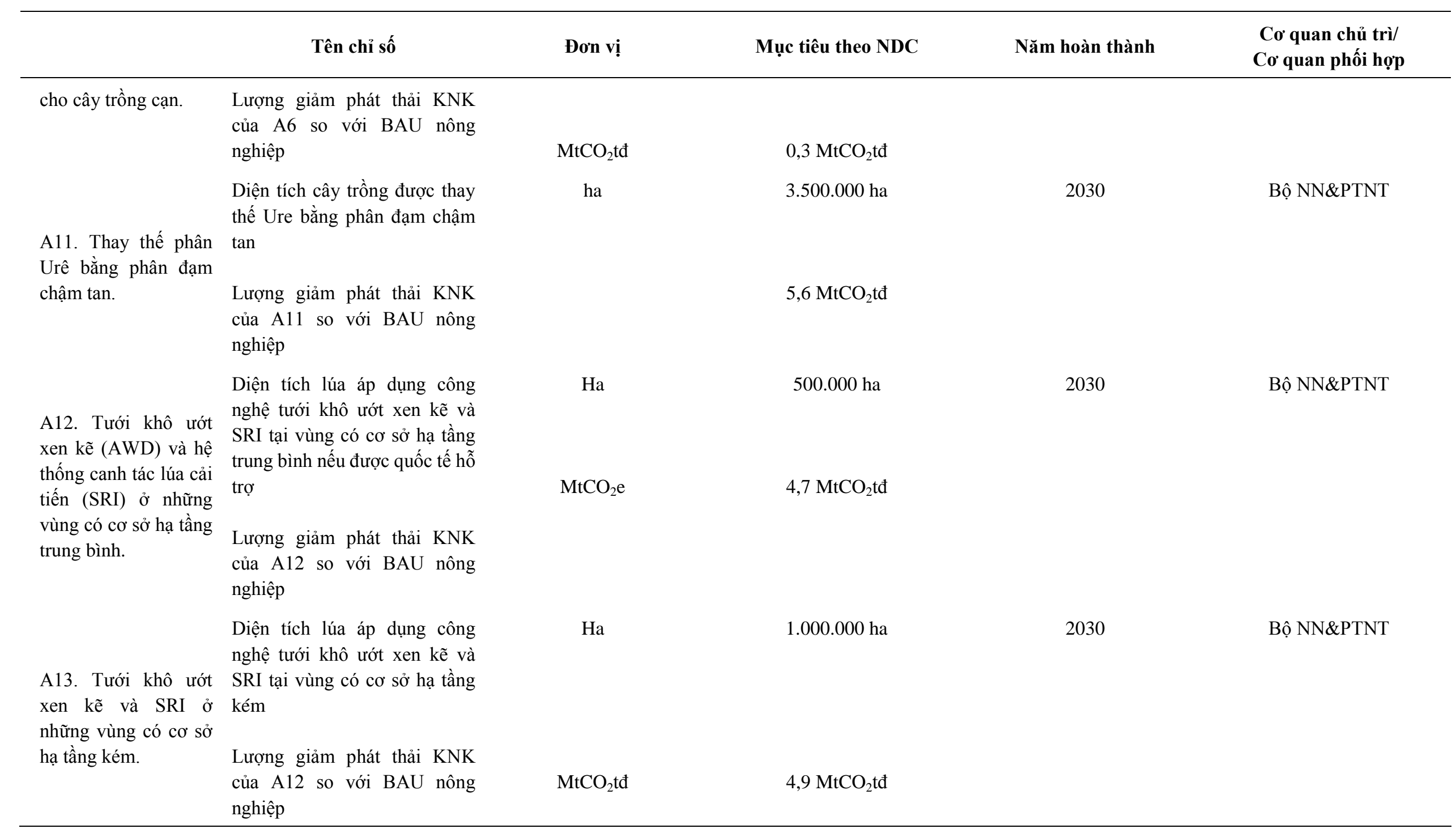




\begin{tabular}{|c|c|c|c|c|c|}
\hline & Tên chỉ số & Đơn vị & Mục tiêu theo NDC & Năm hoàn thành & $\begin{array}{l}\text { Cơ quan chủ trì/ } \\
\text { Cơ quan phối hợp }\end{array}$ \\
\hline \multirow{2}{*}{$\begin{array}{l}\text { A14. Tưới nhỏ giọt } \\
\text { kết hợp bón phân cho } \\
\text { cà phê }\end{array}$} & $\begin{array}{l}\text { Diện tích cà phê áp dụng hệ } \\
\text { thông tưới nhỏ giọt tích hợp } \\
\text { bón phân nếu được quốc tế hỗ } \\
\text { trợ }\end{array}$ & $\mathrm{Ha}$ & 450.000 ha & 2030 & Bộ NN\&PTNT \\
\hline & $\begin{array}{l}\text { Lượng giảm phát thải KNK } \\
\text { của A12 so với BAU nông } \\
\text { nghiệp }\end{array}$ & $\mathrm{MtCO}_{2} \mathrm{tđ}$ & $1,7 \mathrm{MtCO}_{2}$ tđ & & \\
\hline \multirow{2}{*}{$\begin{array}{l}\text { A15. Cải tiến công } \\
\text { nghệ để tái sử dụng } \\
\text { chất thải chăn nuôi } \\
\text { làm phân bón hữu cơ. }\end{array}$} & $\begin{array}{l}\text { Số lượng con gia súc được áp } \\
\text { dụng công nghệ sản xuất chất } \\
\text { thải chăn nuôi làm phân hữu cơ } \\
\text { nếu được quốc tế hỗ trợ }\end{array}$ & Con & 44.000 .000 con & 2030 & Bộ NN\&PTNT \\
\hline & $\begin{array}{l}\text { Lượng giảm phát thải KNK } \\
\text { của A15 so với BAU nông } \\
\text { nghiệp }\end{array}$ & $\mathrm{MtCO}_{2} \mathrm{tđ}$ & 7,5 $\mathrm{MtCO}_{2}$ tđ & & \\
\hline
\end{tabular}




\subsection{Chi số về phát triển bền vĩng}

Nghiên cứu này cũng phát triển các chỉ số phát triển bền vững $(\mathrm{SD})$ để đánh giá tác động của các phương án giảm nhẹ trong NDC được cập nhật của Việt Nam trên ba trụ cột của phát triển bền vững, bao gồm: Phát triển kinh tế, xã hội và bảo vệ môi trường thông qua dánh giá đồng lợi ích (Bảng 3).

Về đồng lợi ích từ các giải pháp giảm nhẹ, đồng lợi ích kinh tế là quan trọng nhất đối với việc mở rộng phát triển và ứng dụng công nghệ. Đồng lợi ích quan trọng thứ hai là lợi ích về thích ứng với $\mathrm{B} Đ K H$, giảm thiểu rủi ro và thiệt hại do thiên tai và tác động của $\mathrm{B} Đ K H$. Ví dụ, tưới nhỏ giọt kết hợp với phân bón cho cà phê là một cách tốt để giảm phát thải khí nhà kính từ việc tiêu thụ năng lượng và giảm $\mathrm{N}_{2} \mathrm{O}$ từ việc bón phân. Điều quan trọng nữa là tiết kiệm nhiều năng lượng bơm nước, giảm phân bón, ổn định năng suất cà phê và sử dụng hiệu quả tài nguyên đất và nước.

Bảng 3. Chỉ số đánh giá tác động của các biện pháp giảm nhẹ KNK trong nông nghiệp đến phát triển bền vững.

\begin{tabular}{|c|c|c|c|}
\hline $\begin{array}{c}\text { Phương án giảm nhẹ } \\
\text { KNK }\end{array}$ & $\begin{array}{c}\text { Chỉ số đánh giá tác động } \\
\text { đến kinh tế }\end{array}$ & $\begin{array}{c}\text { Chỉ số đánh giá tác động } \\
\text { đến xã hội }\end{array}$ & $\begin{array}{l}\text { Chỉ số đánh giá tác } \\
\text { động đến môi trường }\end{array}$ \\
\hline $\begin{array}{l}\text { A1. Tưới khô ướt xen } \\
\text { kẽ (AWD) và hệ } \\
\text { thống canh tác lúa cải } \\
\text { tiến (SRI) ở những } \\
\text { vùng có đủ cơ sở hạ } \\
\text { tầng }\end{array}$ & $\begin{array}{l}\text { - Tỷ lệ lượng nước tưới tiêu } \\
\text { tiết kiệm được }(\%) \text {; } \\
\text { - Tỷ lệ phân bón và thuốc } \\
\text { trừ sâu tiết kiệm được }(\%) \text {. }\end{array}$ & & $\begin{array}{l}\text { Tỷ lệ giảm lượng phát } \\
\text { thải mê-tan }\end{array}$ \\
\hline A2. Rút nước giữa vụ & $\begin{array}{l}\text { - Tỷ lệ lượng nước tưới tiêu } \\
\text { tiết kiệm được }(\%) \text {; } \\
\text { - Tỷ lệ gia tăng năng suất } \\
\text { canh tác }(\%) \\
\text { Reduce } 5-10 \% \text { irrigation } \\
\text { water, } 5 \% \text { increase in yield }\end{array}$ & & \\
\hline $\begin{array}{l}\text { A3. Chuyển đất } \\
\text { chuyên lúa - lúa thành } \\
\text { lúa - thủy sản }\end{array}$ & Tỷ lệ gia tăng thu nhập (\%) & & $\begin{array}{l}\text { Tỷ lệ giảm lượng phát } \\
\text { thải mê-tan }\end{array}$ \\
\hline $\begin{array}{l}\text { A4. Chuyển đất } \\
\text { chuyên lúa thành đất } \\
\text { trồng cây trồng cạn }\end{array}$ & $\begin{array}{l}\text { Tỷ lệ lượng nước tưới tiêu } \\
\text { tiết kiệm được (\%); } \\
\text { Tỷ lệ gia tăng thu nhập (\%) }\end{array}$ & $\begin{array}{l}\text { Tỷ lệ gia tăng thu nhập } \\
(\%)\end{array}$ & $\begin{array}{l}\text { Tỷ lệ giảm lượng tiêu } \\
\text { thụ phân bón và thuốc } \\
\text { trừ sâu }(\%) \text {; } \\
\text { Tỷ lệ giảm lượng phát } \\
\text { thải mê-tan; }\end{array}$ \\
\hline $\begin{array}{l}\text { A5. Cải thiện chất } \\
\text { lượng khẩu phần ăn } \\
\text { cho bò sữa. }\end{array}$ & $\begin{array}{l}\text { Tỷ lệ gia tăng năng suất và } \\
\text { chất lượng sữa (\%) so với } \\
\text { việc sử dụng cách cho ăn } \\
\text { truyền thống }\end{array}$ & & $\begin{array}{l}\text { Tỷ lệ giảm lượng phát } \\
\text { thải mê-tan }\end{array}$ \\
\hline $\begin{array}{l}\text { A6. Cải thiện chất } \\
\text { lượng khẩu phần ăn } \\
\text { cho bò thịt. } \\
\text { A7. Cải thiện chất } \\
\text { lượng khẩu phần ăn } \\
\text { cho trâu. }\end{array}$ & $\begin{array}{l}\text { Tỷ lệ gia tăng năng suất và } \\
\text { chất lượng thịt (\%) } \\
\text { Tỷ lệ gia tăng năng suất và } \\
\text { chất lượng thịt }(\%)\end{array}$ & $\begin{array}{l}\text { Tỷ lệ tăng năng suất lao } \\
\text { động }(\%)\end{array}$ & $\begin{array}{l}\text { Tỷ lệ giảm lượng phát } \\
\text { thải mê-tan }\end{array}$ \\
\hline
\end{tabular}




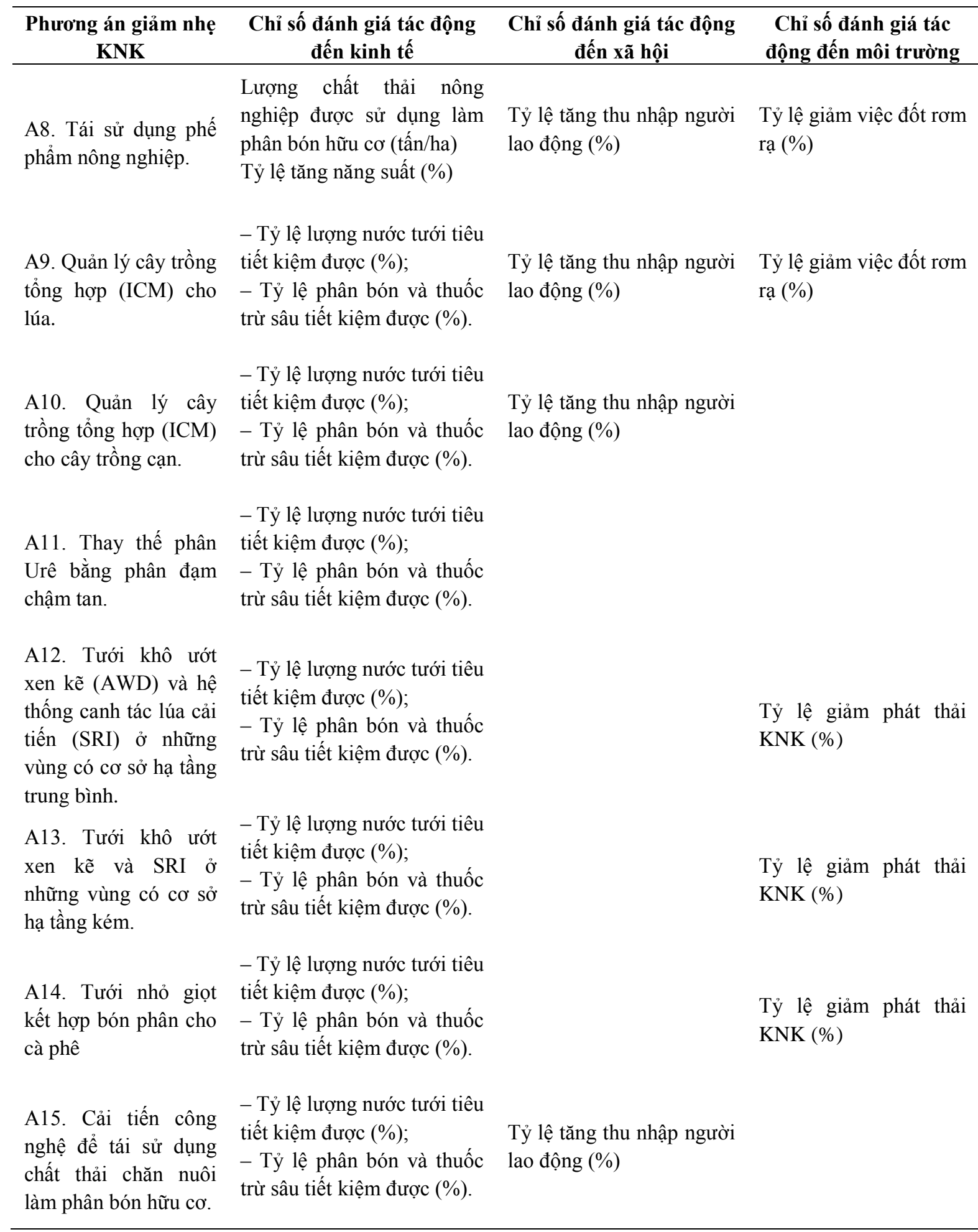

\section{Kết luận}

Để thực hiện cam kết quốc tế về giảm phát thải KNK của Việt Nam, hệ thống MRV đóng vai trò rất quan trọng. Tuy nhiên, ở Việt Nam hiện nay vẫn chưa có bất kỳ quy định hoặc hướng dẫn cụ thể nào cho việc quản lý và thực hiện MRV phát thải KNK nói chung và lĩnh vực nông nghiệp nói riêng. Việc phát triển hệ thống MRV ở cấp quốc gia và cấp ngành là rất quan trọng để đảm bảo việc thực hiện các mục tiêu giảm phát thải KNK cấp quốc gia và cấp ngành như đã nêu trong NDC cập nhật của Việt Nam. Từ góc độ đó, nghiên cứu này đã đề xuất một tổ chức thể chế cho MRV ở cấp quốc gia và bộ chỉ số MRV để theo dõi việc thực hiện các mục tiêu giảm thiểu cho lĩnh vực nông nghiệp trong NDC cập nhật của Việt Nam, 
được chia thành ba loại: (i) Các chỉ số KNK; (ii) Chỉ số hành động và tiến độ và (iii) Chỉ số phát triển bền vững. Các chỉ số này sẽ là cơ sở quan trọng để đo lường và báo cáo các Bộ quản lý ngành về các nỗ lực giảm thiểu. Cần có các nghiên cứu sâu hơn về sắp xếp thể chế cho MRV ở cấp bộ/ngành và áp dụng thí điểm các chỉ số đề xuất trong các lĩnh vực được chọn.

Đóng góp của tác giả: Xây dựng ý tưởng nghiên cứu: P.T.L., N.T.L.; Lựa chọn phương pháp nghiên cứu: N.T.L., Đ.M.T.; Phân tích kết quả: N.T.L., Đ.M.T.; Viết bản thảo nghiên cứu: N.T.L., Đ.M.T.; Chỉnh sửa nghiên cứu: P.T.L., N.T.L., Đ.Q.T.

Lời cảm ơn: Nghiên cứu này được thực hiện trong khuôn khổ của đề tài khoa học công nghệ cấp quốc gia "Nghiên cứu đề xuất hệ thống giám sát-báo cáo-thẩm định $(\mathrm{MRV})$ các hoạt động ứng phó với biến đổi khí hậu ở Việt Nam", mã số BĐKH.32/16-20 thuộc Chương trình Khoa học và Công nghệ ứng phó với Biến đổi khí hậu, Quản lý tài nguyên và môi trường giai đoạn 2016-2020, mã số BĐKH/16-20.

Lời cam đoan: Tập thể tác giả cam đoan nghiên cứu này là công trình nghiên cứu của tập thể tác giả, chưa được công bố ở đâu, không sao chép từ những nghiên cứu trước đây; không có sự tranh chấp lợi ích trong nhóm tác giả.

\section{Tài liệu tham khảo}

1. IPCC. 2006 IPCC Guidelines for National Greenhouse Gas Inventories. IPCC, Kanagawa, 2006.

2. Lütken, S.E.; Dransfeld, B.; Wehner, S.; Agyemang-Bonsu, W.; Avendaňo, F.; Babu, D.; Bonduky, Y.; Carman, R.; Forner, C.; Hinostroza, M.; Kelly, R.; Krey, M.; Sharma, S. Guidance for NAMA design building on country experiences, 2013, pp. 104.

3. Sharma, S.; Desgain, D. Understanding the Concept of Nationally Appropriate Mitigation Action. UNEP Riso Centre on Energy, Technology University of Denmark (DTU), 2013.

4. Center for Clean Air Policy (CCAP). A beginner's guide to building NAMAs, CCAP, 2012.

5. Bộ Tài nguyên và Môi trường. Báo cáo Đóng góp do quốc gia tự quyết định (NDC), 2020.

6. UNEP Risoe Centre. Understanding the concept of NAMAs, 2013. Available at: https://www.transparency-

partnership.net/sites/default/files/2013_unep_risoe_sharma_understanding_namas.p df

7. Thủ tướng Chính phủ. Quyết định số 2053/QĐ-TTg ngày 28/10/2016 của Thủ tướng Chính phủ về việc ban hành Kế hoạch thực hiện Thảo thuân Paris về biến đổi khí hậu. Việt Nam, Hà Nội, 2016.

8. Bộ Tài nguyên và Môi trường. Dự thảo Nghị định Quy định lộ trình và phương thức giảm nhẹ phát thải khí nhà kính. Việt Nam, Hà Nội, 2018.

9. Chính phủ Việt Nam. Luật bảo vệ môi trường sửa đổi, Số 55/2014/QH13, 2014.

10. Thủ tướng Chính phủ. Quyết định số 2359/QĐ-TTg về việc Phê duyệt Hệ thống quốc gia về kiểm kê khí nhà kính. Việt Nam, Hà Nội, 2015.

11. Thủ tướng Chính phủ. Đề án "Quản lý phát thải khí gây hiệu ứng nhà kính; quản lý các hoạt động kinh doanh tín chỉ các-bon ra thị trường thế giới”, Quyết định 1775/QĐ ngày 21 tháng 11 năm 2012, 2012.

12. Lanh, $\mathrm{N}$. Nghiên cứu xây dựng hệ thống đo đạc, báo cáo và thẩm tra $(\mathrm{MRV})$ quốc gia phục vụ quản lý các hoạt động giảm phát thải khí nhà kính ở Việt Nam, 2016. 


\title{
Development of a Measurement-Reporting-Verification System for Mitigation Activities in Agricultural Sector in the NDC of Vietnam
}

\author{
Pham Thanh Long ${ }^{1 *}$, Nguyen Thi Lieu ${ }^{1}$, Dao Minh Trang ${ }^{1}$, Doan Quang Tri ${ }^{2}$ \\ ${ }^{1}$ Institute of Meteorology, Hydrology and Climate Change; \\ phamthanhlong559@gmail.com; lieuminh2011@gmail.com; daominhtrang@gmail.com \\ ${ }^{2}$ Vietnam Journal of Hydrometeorology, Viet Nam Meteorological and Hydrological \\ Administration; doanquangtrikttv@gmail.com
}

\begin{abstract}
Vietnam commits to 9\% reduction in its greenhouse gas emissions compared to the normal development scenario (BAU) with domestic resources, a further reduction of up to $27 \%$ if international support is received by 2030 and proposed many mitigation options to reach those targets. In the updated NDC, Vietnam has allocated mitigation targets across five sectors, notably energy, agriculture, industrial processes (IP), land use, land use change, and forestry. (LULUCF) and waste in the period 2021-2030. Establishment of a national and sectoral measurement, reporting and verification (MRV) system is necessary to track progress towards the GHG emission reduction goals. Currently there is very little research on institutional arrangements and MRV indicators. This study was conducted to develop MRV indicators for GHG mitigation actions in the agricultural sector to assist policy makers in monitoring the implementation of Vietnam's NDC through the following indicators: (i) GHG metrics; (ii) Action and progress indicators and (iii) sustainable development indicators based on relevant studies and close consultation with experts in the agricultural sector.
\end{abstract}

Keywords: MRV; Institutional arrangements; Indicators; Greenhouse gas; Agriculture. 